Bryn Mawr College

Scholarship, Research, and Creative Work at Bryn Mawr College

Graduate School of Social Work and Social

Graduate School of Social Work and Social

Research Faculty Research and Scholarship

Research

2017

\title{
Treatment narratives of suicidal Latina teens
}

Carolina Hausmann-Stabile

Bryn Mawr College, chausmanns@brynmawr.edu

Lauren Gulbas

Luis H. Zayas

Let us know how access to this document benefits you.

Follow this and additional works at: http://repository.brynmawr.edu/gsswsr_pubs

Part of the Social Work Commons

\section{Custom Citation}

Hausmann-Stabile, C., Gulbas, L., Zayas, L.H. 2017. Treatment narratives of suicidal Latina teens. Archives of Suicide Research: 1-8.

This paper is posted at Scholarship, Research, and Creative Work at Bryn Mawr College. http://repository.brynmawr.edu/gsswsr_pubs/77

For more information, please contact repository@brynmawr.edu. 


\section{Treatment Narratives of Suicidal Latina Teens}

\section{Carolina Hausmann-Stabile, Lauren Gulbas \& Luis H. Zayas}

To cite this article: Carolina Hausmann-Stabile, Lauren Gulbas \& Luis H. Zayas (2017): Treatment Narratives of Suicidal Latina Teens, Archives of Suicide Research, DOI: 10.1080/13811118.2017.1304305

To link to this article: http://dx.doi.org/10.1080/13811118.2017.1304305

Accepted author version posted online: 08 Mar 2017.

Published online: 08 Mar 2017.

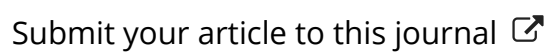

Џ Article views: 11

Q View related articles ¿

View Crossmark data \lceil 


\title{
Treatment Narratives of Suicidal Latina Teens
}

\author{
Carolina Hausmann-Stabile, Lauren Gulbas, and Luis H. Zayas
}

\begin{abstract}
In this article, we examine the treatment narratives of Latina adolescent suicide attempters to understand their experiences undergoing care. For this study, we conducted content and thematic analysis of 68 interviews with Latina adolescent suicide attempters. Most teens who described positive experiences undergoing treatment $(n=39,44.1 \%)$ did so when discussing outpatient mental health services ( $n=30,72.9 \%)$. Latinas felt that the providers who fostered their autonomy and connectedness helped them become active agents in their recovery. Clinicians serving suicidal Latinas must allow them to exercise agency while feeling emotionally connected to providers. To help Latinas manage their suicidality, treatments need to address the teens' developmental needs.
\end{abstract}

Keywords Latina, narratives, suicide attempts, treatment

Latina adolescents report elevated rates of suicide attempts. In 2015, 15.1\% of Latina teens attempted suicide compared to $9.8 \%$ of white and $10.2 \%$ of black girls (Centers for Disease Control and Prevention [CDC], 2016). Research has documented the psychological and sociocultural factors associated with Latinas suicide attempts (Zayas, Gulbas, Fedoravicius, \& Cabassa 2010), yet little is known about the teens' experiences undergoing treatment. Given that approximately one third of Latinas need medical services following a suicide attempt (CDC, 2016), knowledge of their experiences could uncover what clinical practices aid the girls' recovery.

The suicidal behaviors of Latinas indicate acute emotional distress. Suicidal Latinas report intense emotional vulnerability and anguish (Zayas et al., 2010), internalizing and externalizing behaviors (Hausmann-Stabile, Kuhlberg, Zayas, Nolle, \& Cintron, 2012), challenges coping with stressors, and histories of victimization (Gulbas, Hausmann-Stabile, De Luca, Tyler, \& Zayas, 2015). Clinical encounters with Latinas following a suicide attempt offer the opportunity to engage these adolescents in the services they need. In this study, we discuss Latina teens' experiences of treatment following a suicide attempt. We examine the teens' pathways to and characteristics of the services following their suicidal crisis, and what the adolescents made of these experiences. We draw on the participants' narratives to make suggestions to practitioners working with this population.

METHODS

Overview of Study

Data were drawn from a mixedmethod cross-sectional study examining 
the sociocultural, developmental, and familial processes of suicidal Latina adolescents. The study recruited Latinas who had attempted suicide from sites providing medical and mental health services. A suicide attempt was defined as any intentional non-fatal self-injury, no matter how lethal, described by the participant as carrying suicidal intent (O’Carroll et al., 1996). Girls assented and parents consented for participation. From the full sample of participants $(N=122)$, almost two-thirds completed qualitative interviews $(n=73$, $59.8 \%$ ). This paper focuses on a subsample of 68 participants who, during their in-depth interviews, shared their experiences with medical and mental health services.

\section{Qualitative Interviews}

Qualitative interviews were audiotaped and transcribed. Interviewers encouraged participants to discuss the topics included in the interview. Interviews explored: account of the suicide attempt; narratives of treatment post-suicide attempt; and experiences undergoing services. Medical interventions are defined as treatments aimed at stabilizing body functioning. Mental health treatment is defined as any intervention addressing behavioral or emotional problems.

\section{Participants}

Participants were 68 Latina adolescents with suicidal behaviors. The adolescents were between 11 and 19 years old (average age 15 years old). During participation, teens underwent one of the following types of care: outpatient mental health treatment ( $n=47 ; \quad 69.1 \%)$; inpatient psychiatric services $(n=17 ; 25 \%)$; inpatient medical treatment $(n=2 ; 2.9 \%) ;$ or outpatient pediatric care $(n=2 ; 2.9 \%)$. Forty-seven participants $(69.1 \%)$ reported that they had required medical care for their last suicide attempt (see Table 1).
TABLE 1. Participants' Characteristics $(n=68)$

\begin{tabular}{lc}
\hline & $M($ SD $) / N(\%)$ \\
\hline Age & $15.2(0.2)$ \\
US born & $45(66.2 \%)$ \\
Latino cultural group & $22(32.4 \%)$ \\
Puerto Rican & $20(29.4 \%)$ \\
Dominican & $9(13.2 \%)$ \\
Mexican & $17(25 \%)$ \\
Other* & $47(69.1 \%)$ \\
Setting of care at the time of enrollment \\
Outpatient mental health & $17(25 \%)$ \\
Inpatient psychiatric services & $2(2.9 \%)$ \\
Inpatient medical & $2(2.9 \%)$ \\
Outpatient pediatric care & $47(69.1 \%)$ \\
Requiring medical care after &
\end{tabular}

Note. *This includes participants who identified as Colombian, Ecuadorian, Guatemalan, Honduran, Venezuelan, US, and mixed.

Data Analysis

Data analysis combined thematic and content analysis. Thematic analysis focuses on discovering and analyzing patterns in qualitative data (Joffe \& Yardley, 2004). Content analysis is a method of describing and quantifying phenomena (Downe-Wamboldt, 1992). The analysis involved data coding, and the development and analysis of a matrix of coded text. Coding was performed using spreadsheet software, which included organizing segments of text. Author 1 carried out all deductive and inductive coding (Meyer \& Avery, 2009), after which Author 2 reviewed the coding. Any discrepancies were addressed through group consensus (Guest, MacQueen, \& Namey, 2013). Internal validity was derived through systematically documenting the contexts in which themes were mentioned-and validity was facilitated through a team-based approach (Sobo, 2010). Participants' edited quotes are included for illustration 
purposes. To provide a descriptive account of participants' experiences, we present the frequencies of specific themes. Doing so provides important insights into the salience of specific themes across participants (Guest et al., 2013).

\section{FINDINGS}

The analysis of the data revealed four themes emerging from the ways Latina adolescents narrated their experiences of medical and mental health services following a suicide attempt: (1) pathways to services and treatments after a suicide attempt; (2) positive, (3) negative experiences of care, and (4) communication in clinical services.

\section{Pathways to Services and Treatments After a Suicide Attempt}

Three distinct actors led to the initiation of services: adults, peers, and the adolescent attempters themselves. Adults, including relatives, school and medical staff, initiated most of the requests for services $(n=49 ; 72.1 \%)$. Most often, adults requested services after they discovered evidence of an attempt, such as identifying cut marks. "I went to the hospital because I had problems with my bladder. The nurse sent me to the psychiatrist because she saw that I had a scar on my wrist" (17-year-old). Over one-quarter of transfers of the suicidal adolescents to a hospital involved the police $(n=19 ; 27.5 \%)$, when family members $(n=15,22.1 \%)$ or school personnel $(n=3,4.4 \%)$ called 911 to request assistance in managing the behavior that the teens displayed during their suicidal episode.

Although most adolescents did not initiate their own treatments $(n=39$, $56.5 \%$ ), some disclosed their attempt to someone who in turn requested services $(n=19 ; \quad 27.9 \%)$. For example, 6 attempters talked with peers about their suicidal behaviors $(31.6 \%)$, who in turn reached out to school personnel. "My friend took my [suicide note] to the school counselor" (13-year-old). Other teens asked family members for help $(n=13 ; 68.4 \%)$. A small group of girls sought services on their own $(n=4 ; 5.9 \%)$. "I walked into the emergency room, and told that I had to see a doctor right away" (17-year-old). Half of the teens who initiated services on their own $(n=2)$ had received services in the past.

Participants shared their experiences about receiving services at outpatient mental health settings $(n=47 ; 69.1 \%)$, inpatient psychiatric units $(n=17 ; 25 \%)$, inpatient pediatric services $(n=2 ; 2.9 \%)$; and at outpatient pediatric clinics $(n=2$; $2.9 \%$ ). Nearly half of participants were referred to psychiatric inpatient units after receiving services at emergency rooms $(n=33 ; 48.5 \%)$. Most participants referred for inpatient services, along with their suicidality, and displayed aggressive behaviors towards others $(27,81.8 \%)$ ). Adolescents described receiving diverse interventions addressing their suicidal behaviors, including medical treatments $(n=11,16.2 \%)$, talk or behavioral therapy $(n=47$; $69.1 \%)$, and psychotropic medications ( $n$ $=15,22 \%)$. Medications were prescribed to treat depression $(n=6,40 \%)$ or $\operatorname{mood}$ swings $(n=2,13.3 \%)$.

\section{Positive Experiences of Care}

Positive experiences of care were greatly dependent of the contexts in which adolescents received services. For instance, only a fifth of teens admitted to inpatient services described their experiences in positive terms $(n=7,21.2 \%)$. In contrast, most teens who described positive experiences undergoing treatment $(n=39$, $44.1 \%)$ did so when discussing outpatient talk therapy or behavioral services $(n=30$, $72.9 \%)$. 
Inpatient Psychiatric Care. Suicidal Latinas described strategies that they perceived as being helpful during their inpatient stay: (1) providers framed suicidal behaviors within the context of teens' everyday experiences; and (2) clinicians reduced the mental health stigma associated with suicidal thoughts and behaviors. A 16-year-old participant shared, "I told the [E.R.] doctors that I was hearing voices telling me to kill myself, but I was just mad about everything... We were talking [with a clinician] about my life at home, and then she just got it, she knew why I tried to kill myself. She said 'I know you weren't hearing voices. You're just stressed out about everything.' And I was like, 'How does this lady know this stuff?"

Outpatient Mental Health Services. Teens described a range of strategies that their therapist engaged in effective treatments: (1) normalizing experiences; (2) fostering agency; and (3) improving family interactions. For example, some adolescents expressed praise for the therapists who normalized their experiences. "I'm not the only one going through it" (16-year-old). By normalizing the teens' reactions, therapists legitimize their feelings. "I guess talking to the doctors made me understand it's okay to feel sad" (18-year-old). Additionally, adolescents praised providers who fostered their agency. These clinicians invited the teens to exercise free choice in the context of the services they provided. Therapists encouraged the teens' agency in subtle or direct ways. The subtle encouragement could take the form of allowing adolescents to seek answers on their own: "[The therapist] does not want to tell me what to do, she just wants to be there and help me make decisions" (17-yearold). Frequently, the therapists encouraged the teens to become stakeholders in their treatments. Additionally, nine participants described that the positive experiences were related specifically to clinicians who helped them improve their communication and relationship with their families (23.1\%).

Negative Experiences of Care

More than half of the participants shared negative perspectives of their experiences of care $(n=46,67.6 \%)$. These negative experiences were mostly related to: (1) mismatches between the teens' expectations of care and the services provided to them; (2) the stigma associated with psychiatric services; and (3) the teens' feelings of alienation from providers and inability to exercise agency in their recovery.

Emergency Room. The emergency room treatments focus on medical stabilization collided with the suicidal teens' expectation to receive help managing their emotions and family conflicts. "I do need [someone] to talk to because I'm a person that keeps everything to myself so I keep building up and building up" (16-yearold). Adolescents did not feel included in the therapeutic process, and experienced a sense of alienation from those helping them. "I felt weird because [there were] so many people... I saw doctors, supervisors and ... I don't know, people" (16-year-old).

Inpatient Psychiatric Care. Fear and stigma associated with hospitalizations often shaped participants' negative perceptions of inpatient care. This led some adolescents to become disruptive prior to their admission. "I started screaming and yelling, saying I didn't want to go to the hospital. I was scared." (18-year-old). Other teens referred for admission described experiencing a great deal of anxiety because psychiatric in-patient units conjured up popular images associated with asylums. "They're going to send me to a crazy hospital ... they will put me in a straightjacket" (18-year-old). 
Even when fears of the inpatient unit itself dissipated, a different kind of fear emerged-a fear that receiving inpatient services would confirm that they were mentally ill. "I was like, I'm not crazy, so why am I here?... I don't belong here... I wanted to have a normal life." (14-yearold). Teens described inpatient units as sites that greatly constrained their agency, and their descriptions of the settings postadmission shifted from asylum-like to prison-like. "That is not a hospital, that is a jail." (14-year-old). Their narratives of the inpatient unit focused on quantifying the time spent there and on their experiences of limited freedom. They conveyed a sense of being "sentenced" to inpatient units. "They put me in the hospital, and they didn't want to let me out. I [spent] twelve days straight in the hospital" (15-year-old). Discharge was the goal of teens admitted to inpatient care. When the adolescents did not meet the setting's goals, they noted that they concealed their feelings or behaviors from their providers so they would meet the metrics required for discharge. "[I did not tell anybody] because they would have [made] me stay longer" (17-year-old).

Participants differed in evaluating the effectiveness of emergency inpatient care. For some, the negative experiences were framed as a reason to avoid attempting suicide in the future. "I wouldn't try to do that again because being in here is nothing good. Being in here is like if you will be in prison" (17-year-old). Yet, for others, their negative experiences carried different behavioral implications, including avoiding disclosing future suicidality. As another teen disclosed, "When you say things that you really don't mean, you end up in a place that you don't wanna be in... locked up" (14-year-old). Others thought that to avoid inpatient settings, they would need to use more lethal methods in their future suicide attempts. "I don't wanna be here. I'm not trying to do it again, but next time, I will probably do it [worse]" (16-year-old).
Medication Management. Adolescents experienced little agency in the decisions that lead to the prescription of medications. "They put me on a lot of different medications. First they put me on [Zolpidem], and then they gave me [Citalopram], and then they said it was making me hyper; so they gave me lithium because they would say that I had mood swings. I kind of just take them" (16-year-old). The teens exercised agency by discontinuing medications without medical supervision, especially in those cases in which they did not feel closeness with their providers. "I wasn't comfortable talking to the doctor so I just stopped going and taking the medication" (17-year-old).

\section{Communication in Clinical Services}

Central to the treatment narratives of almost all participants $(n=67,98.5 \%)$ were the "ways of speaking and listening" (Epele, 2016, p. 2) that the teens encountered while receiving services. These narratives can be grouped within three themes: (1) the cathartic effect of communicating distress; (2) how communication fosters human connection; and (3) perspectives on communicating with clinicians. The most immediate positive effect of treatment, independently of setting, was to allow suicidal teens to share their distress. Sharing their distress lead to experiences of emotional relief. "Whenever I am stressed out, to relieve my stress I talk to someone" (16-years-old). Clinical strategies that fostered dialogue between the teens and their providers improved the girls' feelings of being connected, ameliorating their sense of loneliness and isolation. "I got people right here that I know they can help me. I don't feel alone any more" (16-yearold). Clinicians assisted the adolescents to improve the communication with their family members: "my therapist told me I had to tell [my father] what [had] happened. [She] helped me tell him" 


\section{TABLE 2. Latina Adolescents' Positive and Negative Treatment Perceptions and Implications for Clinicians}

\begin{tabular}{|c|c|c|}
\hline $\begin{array}{l}\text { Treatment } \\
\text { modality }\end{array}$ & Perception & Implications \\
\hline $\begin{array}{l}\text { Emergency } \\
\text { room }\end{array}$ & $\begin{array}{l}\text { Negative } \\
\text { Limited contact with providers } \\
\text { Limited agency }\end{array}$ & $\begin{array}{l}\text { Clinicians' could offer patients opportunities to } \\
\text { talk about their feelings and debrief their } \\
\text { service experiences } \\
\text { Involve patients in post-discharge treatment } \\
\text { decisions }\end{array}$ \\
\hline \multirow[t]{4}{*}{$\begin{array}{l}\text { Psychiatric } \\
\text { inpatient }\end{array}$} & $\begin{array}{l}\text { Positive } \\
\text { Opportunities for extended } \\
\text { contact with providers }\end{array}$ & $\begin{array}{l}\text { Foster communication with providers and } \\
\text { family members }\end{array}$ \\
\hline & Negative & Psychoeducation \\
\hline & Stigma & Reduce mental health stigma \\
\hline & Limited agency & Offer opportunities to exercise agency \\
\hline \multirow[t]{2}{*}{$\begin{array}{l}\text { Outpatient } \\
\text { mental } \\
\text { health }\end{array}$} & Positive & Psychoeducation \\
\hline & $\begin{array}{l}\text { Normalize experience } \\
\text { Developmentally-appropriate } \\
\text { clinical approaches } \\
\text { Helped adolescents improve } \\
\text { communication with parents } \\
\text { Fostered dialogue with teens }\end{array}$ & $\begin{array}{l}\text { Introduce treatment modalities that improve } \\
\text { communication, and address developmental } \\
\text { processes and family functioning }\end{array}$ \\
\hline
\end{tabular}

(13-year-old). Some parents were described by the teens as recognizing that the girls benefited from talking to clinicians. "[My mother] tells me, "tell the guidance counselor." Other parents, who perhaps were not aware of the confidentiality guidelines for clinical services were less supportive of the adolescents' openness to providers. " $[\mathrm{My}$ mother told me] that my statements will be written in my record. Now people are going to see in my record that I received psychological services, and they will think poorly of me. I will not be able to get a job” (13-year-old) (see Table 2).

\section{DISCUSSION}

In this article, we used data from in-depth interviews with suicidal Latina teens to explore the treatments they received post-suicide attempt and the participants' perceptions of these experiences. Suicidal Latinas' experiences receiving care were greatly dependent on the settings in which the services were delivered. In general, more restrictive settings such as emergency rooms and inpatient units were perceived more negatively by the teens, while outpatient care was described more positively. This may be in part because the more restrictive settings produced several disconnects between treatment modalities and clinical objectives, on one hand, and goals and needs of Latina suicide attempters, on the other hand. For instance, the emergency room treatment modality focused on medical stabilization through bodily interventions. The adolescents, on the contrary, arrived at the emergency room 
seeking emotional support and understanding of their interpersonal crises. Furthermore, the interventions used in the emergency room mimicked the suicidal adolescents' coping style of addressing emotional and interpersonal crises through bodily interventions. The mismatch between clinical and patient needs may help to explain, in part, why so many Latina adolescents felt that mental health providers in restrictive settings did not help them with their suicidality.

Participants who found mental health treatments helpful described providers who fostered communication, allowed them to exercise agency, and helped them improve their relationships with family members. Providers accomplished these tasks by encouraging dialogue with the teens, which in turn fostered attachment, and turned adolescents from patients into stakeholders in their recovery. Inviting teens to make decisions about their treatments aligned with the adolescents' developmental needs of exercising autonomy. Lastly, helpful clinicians facilitated more effective communications between the adolescents and their caregivers. This helped reduce the teens sense of loneliness and alienation as well as the interpersonal conflicts associated with the girls' suicidal behaviors (Zayas, 2011).

\section{Limitations}

We recommend caution when generalizing these findings. First, the original study was not designed to study the treatment narratives of Latina suicidal adolescents. Moreover, we do not have any information from girls who did not have contact with providers after their suicide attempts, as they were not enrolled in the original study. Despite these limitations, our study provides important insights for clinicians treating suicidal Latina adolescents.
Conclusion

We draw on the participants' treatment narratives to inform three suggestions for providers caring for suicidal Latina teens. First, providers could implement treatment modalities that allow teens to feel connected. This can be done by fostering communication between providers and adolescents, and between teens and their families. Second, providers should deliver interventions addressing the interpersonal tensions the teens are experiencing with their families. Such interventions would enhance the family communication and functioning. Last, clinicians could focus on delivering developmentally attuned interventions to suicidal Latina teens. This could be done, for instance, by inviting them to practice decision-making in the context of treatment.

\section{AUTHOR NOTE}

Carolina Hausmann-Stabile, School of Social Work, Temple University, Philadelphia, Pennsylvania, USA.

Lauren Gulbas, School of Social Work, University of Texas at Austin, Austin, Texas, USA.

Luis H. Zayas, School of Social Work, University of Texas at Austin, Austin, Texas, USA.

Correspondence concerning this article should be addressed to Carolina Hausmann-Stabile, PhD, School of Social Work, Temple University, Ritter Annex 5th floor, $1301 \mathrm{~W}$. Cecil B. Moore Avenue, Philadelphia, PA 19122-6091, USA. E-mail: tug29052@temple.edu

\section{FUNDING}

Support was provided by NIMH grant R01MH070689 (PI: Zayas), and by Dr. Hausmann-Stabile Start-Up Research Funds at Temple University. 


\section{REFERENCES}

Centers for Disease Control \& Prevention. (2016). Surveillance summaries: Youth risk behavior surveillance-United States, 2015. Morbidity and Mortality Weekly Report, 65(6), 1-174. doi:10.15585/mmwr.ss6506a1

Downe-Wamboldt, B. (1992). Content analysis: Method, applications and issues. Health Care for Women International, 13, 313-321. doi:10.1080/ 07399339209516006

Epele, M. E. (2016). Psychotherapy, psychoanalysis and urban poverty in Argentina. Anthropology \& Medicine, 23, 244-258. doi:10.1080/13648470.2016.1180664

Guest, G., MacQueen, K. M., \& Namey, E. E. (2013). Applied thematic analysis. Los Angeles, CA: Sage.

Gulbas, L. E., Hausmann-Stabile, C., De Luca, S. M., Tyler, T. R., \& Zayas, L. H. (2015). An exploratory study of nonsuicidal self-injury and suicidal behaviors in adolescent Latinas. American Journal of Orthopsychiatry, 85(4), 302. doi: $10.1037 /$ ort 0000073

Hausmann-Stabile, C., Kuhlberg, J. A., Zayas, L. H., Nolle, A. P., \& Cintron, S. L. (2012). Means, intent, lethality, behaviors, and psychiatric diagnosis in Latina adolescent suicide attempters.
Professional Psychology: Research and Practice, 43(3), 241. doi:10.1037/a0026258

Joffe, H., \& Yardley, L. (2004). Content and thematic analysis. In D. F. Marks \& L. Yardley (Eds.), Research methods for clinical and health psychology (pp. 56-68). Thousand Oaks, CA: SAGE Publications.

Meyer, D. Z., \& Avery, L. M. (2009). Excel as a qualitative data analysis tool. Field Methods, 21(1), 91-112. doi:10.1177/1525822x08323985

O'Carroll, P. W., Berman, A. L., Maris, R. W., Moscicki, E. K., Tanney, B. L., \& Silverman, M. M. (1996). Beyond the Tower of Babel: A nomenclature for suicidology. Suicide and LifeThreatening Behavior, 26(3), 237-252.

Sobo, E. J. (2010). Culture and meaning in health services research. Walnut Creek, CA: Left Coast Press.

Zayas, L. H. (2011). Latinas attempting suicide: When cultures, families, and daughters collide. New York, NY: Oxford University Press.

Zayas, L., Gulbas, L. E., Fedoravicius, N., \& Cabassa, L. J. (2010). Patterns of distress, precipitating events, and reflections on suicide attempts by young Latinas. Social Science \& Medicine, 70(11), 1773-1779. doi:10.1016/j. socscimed.2010.02.013 